\title{
Mixed Crystal Disease: A Tale of 2 Crystals
}
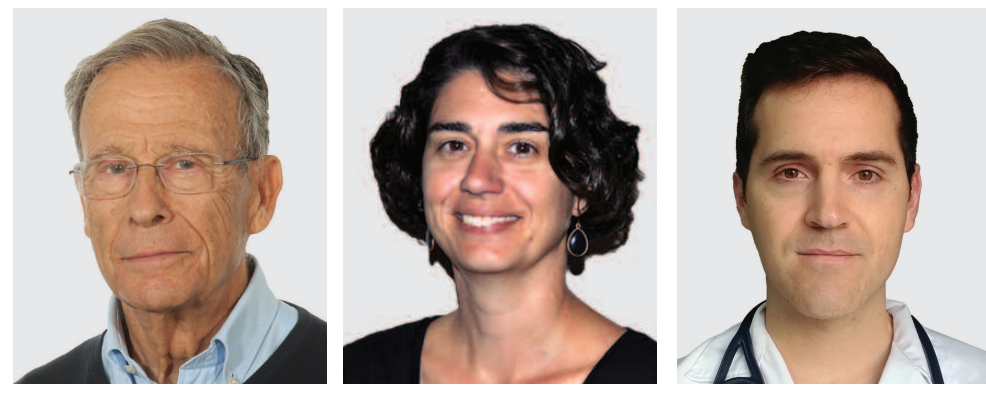

A report published in this issue of The Journal estimated the recurrence rate of acute calcium pyrophosphate (CPP) crystal arthritis and its associated factors ${ }^{1}$ on 111 patients with a first acute flare of CPP arthritis. Of these, 13 were considered to have gout on top of fulfilling the study's definition of acute CPP crystal arthritis: 1 had monosodium urate (MSU) crystals documented on a different occasion in a different joint, 1 had simultaneous observation of MSU and CPP crystals in the same joint, 7 had prior podagra, and 4 had been diagnosed with gout based on elevated uric acid and synovitis in a joint different from that in which CPP arthritis was diagnosed. At the very least, the patient with both crystal types in the same joint - and likely some of the others - could be classified as having mixed crystal disease. Aside from occasional data, little is known about this condition.

The formation of MSU crystals is a consequence of hyperuricemia, and at least some of the mechanisms of crystal formation appear similar to those of biomineralization ${ }^{2}$; other factors likely influence the nucleation of the crystals ${ }^{3}$. At the joint, MSU crystals form on the surface of the joint cartilage and their passage to and presence in the joint fluid is constant, after the first flare ${ }^{4}$. It is likely that this appearance in the synovial fluid (SF) is initiated earlier, at the stage of apparent asymptomatic hyperuricemia (preclinical gout with deposits), but before the first symptomatic flare ${ }^{5}$. Gout has been associated with osteoarthritis (OA) in the affected joints ${ }^{6}$.

The keys to the formation of CPP crystals are less clear. Sufficient, but poorly determined, concentrations of ionized calcium and pyrophosphate appear to be crucial ${ }^{7}$. CPP crystals form in the middle zone of the joint cartilage ${ }^{8}$ and their passage into the joint cavity appears necessary for arthritis flares. Of interest, chondrocalcinosis (CC) has been described in joints damaged by different mechanisms: after meniscectomy ${ }^{9}$, in previously traumatized ${ }^{10}$ and unstable ${ }^{11}$ joints, as a late finding in patients with juvenile arthritis ${ }^{12}$, or in joint dysplasias ${ }^{13}$. In a report retrospectively reviewing the presence of crystals in SF of different disease ${ }^{14}$, CPP crystals were found in 185 of 830 SF samples (22\%) from patients with OA and in 27 of 326 SF samples (8\%) from patients with rheumatoid arthritis, whose disease duration and radiologic joint damage were not given. In a more stringent, prospective search in knee joints of patients with $\mathrm{OA}$, the same group found CPP crystals in 23/74 SF samples $(31 \%)^{15}$. Also, the prevalence of CC - and CPP crystal arthropathy - rises with age, and has been reported in up to $44 \%$ of subjects over 84 years of age ${ }^{16}$, an age at which OA is usual. In 6 out of 80 gouty SF samples analyzed after cytocentrifugation, a few CPP crystals were found along with the MSU crystals. In every patient, the fluid was obtained from knee joints with an intermediate or high grade of $\mathrm{OA}^{17}$. Taken together, these reports suggest that the deposit of CPP crystals likely is a part of the remodeling process in damaged joints, which could explain the concurrence of CPP crystals with other processes, including gout, in which joints can be damaged and then repaired.

The term mixed crystal disease was coined for those cases in which both MSU and CPP crystals are found together in the SF. The problem has not been subjected to systematic study and its prevalence and clinical consequences remain uncertain. MSU and CPP crystals have different characteristics under the bright light, polarized, and compensated microscopes ${ }^{18}$ that allow an accurate identification by trained observers ${ }^{19}$. Finding both CPP and MSU crystals in sizable numbers in the same joint fluid is, in our experience, quite unusual. However, missing a small number of one of the crystals in the presence of sizable numbers of the other - and so, having satisfactorily answered the clinical question - might be easy, especially if the search is conducted only under polarized light microscopy, given the modest to absent birefringence of CPP crystals $^{20}$. Also, identifying crystals at low numbers depends on the effort and time spent in the microscopic examination. A major problem is the crystal count threshold from which crystals must be deemed pathogenic; occasional CPP crystals have

See CPP crystal arthritis flares and recurrence, page 1261

Personal non-commercial use only. The Journal of Rheumatology Copyright @ 2020 . All rights reserved. 
uncertain clinical significance, while MSU crystals always mean gout.

An interesting study presented at several meetings but to our knowledge still unpublished ${ }^{21}$ aimed to determine the proportion of patients diagnosed with gout who also had CPP crystal disease (investigated by SF analysis, radiography, and/or sonography), and the proportion of patients with CPP crystal arthritis who also had a diagnosis of gout. Out of 794 patients with gout, 57 (7\%) also had CPP crystal deposition; in 15 of them, CPP and MSU crystals were both present in an SF sample.

To gain information on the differential characteristics of mixed crystal arthritis, it is necessary to conduct prospective studies, searching for CPP crystals with care in joints affected by gout with and without $\mathrm{OA}$, a probable common facilitator for the formation of both crystal types. Crystal arthritis of either type responds to the same drugs, and most likely mixed crystal disease does too. In the management of patients with coincidental gout and CPP crystal disease, dissolution of crystals is only feasible in gout and its current treatment is aimed to completely eliminate them. Management of CPP crystal disease is based on treating the acute flares, or if clinical inflammation is more continuous or repetitive, the use of colchicine or a small dose of a nonsteroidal antiinflammatory drug. The interleukin 1 blockers anakinra and canakinumab can have a role in the exceptional patient. Anecdotally, we have seen 2 patients with crystal proven gout who, after prolonged reduction of uricemia (enough to have dissolved MSU crystals), attended our clinics with an acute episode of knee arthritis that they considered to be gout. CPP crystals were found in the SF of both. In acute flares of arthritis occurring after adequate gout treatment, SF analysis appears thus mandatory, even in patients with a previous crystal-proven gout diagnosis.

\section{ELISEO PASCUAL (iD, MD, PhD,}

Department of Medicine, University Miguel Hernandez, Elche; and Instituto de Investigación Sanitaria y Biomédica de Alicante (ISABIAL), Alicante; FRANCISCA SIVERA (D), MD, $\mathrm{PhD}$

\section{Department of Medicine,}

University Miguel Hernandez, and Department of Rheumatology,

Hospital General Universitario Elda, Elda;

MARIANO ANDRES (iD, MD, $\mathrm{PhD}$,

Department of Medicine,

University Miguel Hernandez, and ISABIAL, and Department of Rheumatology,

Hospital General Universitario Alicante,

Alicante, Spain.

Address correspondence to Prof. E. Pascual, Universidad Miguel Hernandez, Carretera Nacional 332 s/n, 03550, San Juan de Alicante, Alicante, Spain. E-mail: pascual_eli@gva.es

\section{REFERENCES}

1. Yates KA, Yoshida K, Xu C, Lyu H, Norvang V, Solomon DH, et al.
Acute calcium pyrophosphate crystal arthritis flare rate and risk factors for recurrence. J Rheumatol 2020;47:1261-6.

2. Pascual E, Addadi L, Andrés M, Sivera F. Mechanisms of crystal formation in gout-a structural approach. Nat Rev Rheumatol 2015;11:725-30.

3. Chhana A, Pool B, Wei Y, Choi A, Gao R, Munro J, et al. Human cartilage homogenates influence the crystallization of monosodium urate and inflammatory response to monosodium urate crystals: a potential link between osteoarthritis and gout. Arthritis Rheumatol 2019;71:2090-9.

4. Pascual E, Batlle-Gualda E, Martínez A, Rosas J, Vela P. Synovial fluid analysis for diagnosis of intercritical gout. Ann Intern Med 1999;131:756-9.

5. De Miguel E, Puig JG, Castillo C, Peiteado D, Torres RJ, Martín-Mola E. Diagnosis of gout in patients with asymptomatic hyperuricaemia: a pilot ultrasound study. Ann Rheum Dis 2012;71:157-8.

6. McCarthy GM, Durcan L. Crystal arthritis: Crystallizing our ideas about gout and osteoarthritis. Nat Rev Rheumatol 2017;13:698-9.

7. Bennett RM, Lehr JR, McCarty DJ. Factors affecting the solubility of calcium pyrophosphate dihydrate crystals. J Clin Invest 1975;56:1571-9.

8. Rosenthal AK, Ryan LM. Calcium pyrophosphate deposition disease. N Engl J Med 2016;374:2575-84.

9. Doherty M, Watt I, Dieppe PA. Localised chondrocalcinosis in post-meniscectomy knees. Lancet 1982;1:1207-10.

10. deLange EE, Keats TE. Localized chondrocalcinosis in traumatized joints. Skeletal Radiol 1985;14:249-59.

11. Settas C, Doherty M, Dieppe P. Localised chondrocalcinosis in unstable joints. Br Med J (Clin Res Ed) 1982;285:175-6.

12. Doherty M, Dieppe PA. Pyrophosphate arthropathy as a late complication of juvenile chronic arthritis. J Rheumatol 1984;11:219-21.

13. Sambrook PN, de Jager JP, Champion GD, Doust BD, McGirr EE, Kozlowski KS, et al. Synovial complications of spondylepiphyseal dysplasia of late onset. Arthritis Rheum 1988;31:282-7.

14. Oliviero F, Scanu A, Galozzi P, Gava A, Frallonardo P, Ramonda R, et al. Prevalence of calcium pyrophosphate and monosodium urate crystals in synovial fluid of patients with previously diagnosed joint diseases. Joint Bone Spine 2013;80:287-90.

15. Frallonardo P, Oliviero F, Peruzzo L, Tauro L, Scanu A, Galozzi P, et al. Detection of calcium crystals in knee osteoarthritis synovial fluid: a comparison between polarized light and scanning electron microscopy. J Clin Rheumatol 2016;22:369-71.

16. Wilkins E, Dieppe P, Maddison P, Evison G. Osteoarthritis and articular chondrocalcinosis in the elderly. Ann Rheum Dis 1983;42:280-4.

17. Robier C, Neubauer M, Quehenberger F, Rainer F. Coincidence of calcium pyrophosphate and monosodium urate crystals in the synovial fluid of patients with gout determined by the cytocentrifugation technique. Ann Rheum Dis 2011;70:1163-4.

18. Pascual E, Sivera F. Synovial fluid crystal analysis. In: Gout and other crystal arthropathies. Terkeltaub R, editor. Philadelphia: Elsevier Saunders; 2012:20-34.

19. Lumbreras B, Pascual E, Frasquet J, González-Salinas J, Rodríguez E, Hernández-Aguado I. Analysis for crystals in synovial fluid: training of the analysts results in high consistency. Ann Rheum Dis 2005;64:612-5.

20. Ivorra J, Rosas J, Pascual E. Most calcium pyrophosphate crystals appear as non-birefringent. Ann Rheum Dis 1999;58:582-4.

21. Perez-Ruiz F, Castillo E, Chinchilla SP, Herrero-Beites AM. Coexistence of gout and pyrophosphate arthritis in two large cohorts: hyperuricemia as a factor for clinical misdiagnosis [abstract]. Ann Rheum Dis 2014;73 Suppl 2:776.

J Rheumatol 2020;47:1158-9; doi:10.3899/jrheum.191316 Personal non-commercial use only. The Journal of Rheumatology Copyright @ 2020 . All rights reserved. 